\title{
I'm Too Clever for this Job: a Bivariate Probit Analysis on Overeducation and Job Satisfaction in Australia
}

\section{Christopher M. Fleming ${ }^{\mathrm{a}}$ and Parvinder Kler ${ }^{\mathrm{b}, *}$}

\author{
${ }^{a}$ School of Economics, University of Queensland, St Lucia 4072, Australia \\ ${ }^{\mathrm{b}}$ Centre for Economic Policy Modelling (CEPM), School of Economics, University of Queensland, St \\ Lucia 4072, Australia
}

Using data from the first wave of the Household, Income and Labour Dynamics in Australia (HILDA) dataset, this paper establishes an empirical relationship between overeducation and workplace satisfaction for Australian adult males in the labour force. In a departure from much of the existing literature, both univariate and bivariate probit models are used to account for potential unobserved heterogeneity. In support of our decision to employ bivariate probit models, we find evidence of a positive correlation between the unobserved factors affecting overeducation and three of six measures of workplace satisfaction. While levels of satisfaction remain high, results show that across all measures overeducated workers are less satisfied than their nonovereducated counterparts. This intimates that satisfaction levels should be viewed from a relative, rather than an absolute perspective.

\footnotetext{
* Corresponding author. E-mail: p.kler@economics.uq.edu.au
} 
"Pleasure in the job puts perfection in the work"

Aristotle 384BC - 322BC

\section{Introduction}

The Australian adult population are among the most educated in the OECD; only Norway, the Netherlands, Iceland, Germany and Denmark report higher levels of educational attainment (OECD, 2004). As laudable as this achievement is on the surface, such a high level of attainment is not without its pitfalls. Foremost among these is that highly educated labour forces can experience higher rates of educationjob mismatch, or overeducation. ${ }^{1}$ This in turn may have implications for an economy's level of growth, for while being well-educated is generally considered important to an individual's social and economic well-being, there is evidence to suggest that being overeducated in the labour market can lead to reduced job satisfaction and lower productivity (Tsang, 1987; Tsang, et al., 1991).

This paper, using six different measures of workplace satisfaction, investigates the relationship between overeducation and job satisfaction in the Australian labour market, extending the existing literature in two ways: It is the first study of overeducation and job satisfaction in Australia and, unlike previous research, we employ bivariate probit modelling (Greene, 1997). Previous studies have tended to use univariate probit modelling. However, there is potential for the univariate probit method to produce biased results if, as we suspect, an overlap exists between unobserved characteristics that determine both overeducation and job satisfaction; the bivariate approach offers a solution to this problem.

\footnotetext{
${ }^{1}$ Overeducation is said to occur if a worker has excess education to that needed to perform his or her job. See Hartog (2000) for more information.
} 
An Australian focus is timely as the Commonwealth government, having gained control of both legislative houses in the 2004 election, has recently introduced widesweeping reforms to Australia's workplace relations system; purportedly the most substantial changes since the Conciliation and Arbitration Act was passed in 1904 (Andrews, 2005). Proponents suggest that the reforms will introduce a much needed level of flexibility into workplace relations. Opponents, however, suggest that the reforms will shift the balance of power towards employers, leading to lower real wages and deterioration in working conditions. Whatever the outcome, it is likely that the reforms will alter the relationship between overeducation and job satisfaction; it is therefore useful to present a pre-reform snapshot of the overeducation-job satisfaction situation.

In Section II we present a brief summary of the literature that explicitly links overeducation and satisfaction. Section III presents information on the dataset used, variable definitions and summary statistics, while Section IV states the specific hypotheses to be tested and presents descriptive data. Methodology is discussed in Section V. Section VI presents the modelling results. Finally, Section VII discusses and concludes.

\section{Background}

Compared to other fields of overeducation research, difficulties with, or a complete absence of, data has led to the overeducation-job satisfaction relationship being largely untested. The first to explicitly model this relationship, Tsang and Levin (1985) form a hypothesis on evidence in the industrial-psychology literature, which finds counter-productive behaviour in the workplace amongst those with more 
education than that required for their jobs. ${ }^{2}$ In this scenario, overeducation may result in reduced work effort, increased production cost and thus, lower productivity. Following the construction of a firm-based production model (the 'Tsang-Levin' model), the authors conclude that overeducation, via lower job satisfaction, leads to not only lower productivity at the individual level, but also lower profits at the level of the firm. Using data from United States communication companies, Tsang (1987) finds empirical evidence in favour of the hypothesis behind the Tsang-Levin model. Using a broader cross-industry data set, Tsang et al. (1991) confirm that surplus education is negatively related to job satisfaction and other correlates of productivity. Further, they report higher turnover for males with particularly high levels of surplus education.

Using data from employees of Oregon manufacturing and warehouse firms, Hersch (1991) finds evidence to support her supposition that overeducated workers are less satisfied and more likely to resign than adequately educated workers. In a subsequent study (Hersch, 1995), she finds that overeducated workers receive less on-the-job training and are more likely to be promoted. A result she suggests rationalises firms' decisions to hire mismatched workers. ${ }^{3}$

This positive relationship between promotion and overeducation is not found in Battu et al.'s (2000) study of UK graduates. The authors report that overeducated workers rate their promotion prospects lower than the adequately educated. Furthermore, they find no evidence of employers upgrading tasks given to the overeducated. In a more recent study of Belgian school leavers, Verhaest and Omey (2004) report that, once

\footnotetext{
${ }^{2}$ It is often assumed that education is positively related to productivity, at least from the view point of human capital theory. See for example Nelson and Phelps (1966), Welch (1970) and Schultz (1975).

${ }^{3}$ Hersch hypothesises that firms hire overeducated workers because they require less training in their starting positions and form a pool from which promotions are made. This reduces hiring costs for higher-level positions in the firm.
} 
attained education is controlled for, overeducated workers are less satisfied, more mobile, participate less in training and earn less than adequately educated workers.

In contrast to these findings, Buchel (2002), looking at the effect of overeducation on worker productivity within German firms, finds no significant difference in job satisfaction between overeducated and adequately educated employees. Furthermore, the overeducated are reported to be healthier, more work and career minded, have more on-the-job training and have longer tenure than their adequately educated counterparts. The generality of his results, however, is somewhat limited by his sample, which is restricted to those working in low skill jobs that require few formal qualifications.

Common to all of the aforementioned studies is the use of overeducation as a measure of mismatch between a worker's qualifications and the qualifications needed to perform his or her job. Allen and van der Velden (2001) differentiate between education and skill mismatches, finding only a weak relationship between the two. Crucially, they find a significant negative relationship between skill mismatch and job satisfaction, while the link between education-mismatch and job satisfaction is found to be insignificant. ${ }^{4}$

\section{Data}

Data is obtained from the first (2001) wave of the Household, Income and Labour Dynamics in Australia (HILDA) dataset. ${ }^{5}$ Wave 1 begins with an initial sample of 13,969 individuals who filled out the Person Questionnaire, of whom 6,622 or 47.40\% are males. Of these, 4,479 or $67.64 \%$ are employed. After checking for inconsistencies in the data and removing individuals with incomplete answers we end

\footnotetext{
${ }^{4}$ We are unable to replicate this distinction as our dataset does not contain enough information to separate educational qualifications and skill levels.

${ }^{5}$ For more information on Wave 1 of the HILDA dataset see Wooden et al. (2002).
} 
up with a figure of 3,006 individuals, of whom 1,030 (34.26\%) are overeducated and 1,976 (65.74\%) are either under or adequately educated (“non-overeducated”). ${ }^{6}$

The HILDA dataset provides a rich source of information on labour market participation, outcome and performance. There is information on firm size, union membership, industry type and length of employment. Socio-demographic data include age, place of birth, marital status and number of years in formal education. Appendix 1 provides a complete list of variables and definitions used in this study.

Of particular interest, HILDA contains detailed information on workplace satisfaction. Respondents are asked to choose a number between 0 and 10 to indicate their levels of satisfaction with a range of workplace satisfaction measures. The various measures are overall job satisfaction, satisfaction with pay, satisfaction with job security, satisfaction with hours of work, satisfaction with (type of) work and satisfaction with the flexibility to balance work and non-work commitments (job flexibility). ${ }^{7}$

For the purposes of this paper, dummy variables are created for each of the satisfaction measures. Those with a value of 6 to 10 are assigned as being satisfied (satisfaction measure $=1$ ) while those answering 0 to 5 are assigned as being dissatisfied (satisfaction measure $=0){ }^{8}$

\footnotetext{
${ }^{6}$ The undereducated are job mismatched insofar as they possess paper qualifications beneath their job requirements. However, undereducation is not a concern for policymakers as the undereducated tend to be more experienced workers with longer tenure at work. As the undereducated are not deemed a disadvantaged group in the labour market, a number of other studies in the education-job mismatch literature have also concentrated their research only on the overeducated. See for example Duncan and Hoffman (1981), Alba-Ramirez (1993) and Battu and Sloane (2004). In unreported results, we find the undereducated to be older, have more working experience and have longer tenure than both the over and adequately educated. In essence, we surmise that these workers have been promoted into their jobs, in the absence of appropriate paper qualifications, because they have developed the necessary skills to do that job.

${ }^{7}$ The workplace satisfaction question given to respondents (E36 of the Person Questionnaire) is reproduced as Appendix 2.

${ }^{8}$ We also investigate more stringent restrictions on the identification of satisfaction dummies in order to test the robustness of our original measure. Specifically, we narrow the definition of satisfaction to
} 
The means and standard deviations of the explanatory variables for overeducated and non-overeducated individuals are presented in Table $1 .^{9}$ We find a number of differences between the two groups. Namely, overeducated workers have spent more time in education, but less in their current position. They are younger, earn less and are less likely to be married or in a de facto relationship (couple). Further, they are more likely to be recent immigrants, especially those from non-English speaking background (NESB) countries, work part-time or casually and for a small firm. The overeducated are under-represented in the public services. These results largely match previous findings on the differences between the overeducated and non-overeducated in Australia (Battu and Sloane, 2004; Kler, 2005a; Voon and Miller, 2005; Green, et al., 2006; Kler, 2006)

\section{Hypotheses and Descriptive Data}

It is clear from the background discussion that many studies report a significant negative relationship between overeducation and job satisfaction. Further, following the stylised facts of overeducation, it has long been established that the overeducated earn a smaller premium for their excess education compared to their required education, and that they earn less than similarly qualified well-matched colleagues (Hartog, 2000). Furthermore, there is evidence that relative, rather than absolute, wages determine satisfaction with pay (Clark and Oswald, 1996). For example, while the overeducated might earn more than their immediate colleagues doing the same job, they might still be dissatisfied with their pay compared to their similarly qualified peers who are in well-matched employment. In this paper, we therefore hypothesise

include only those who answered by giving a value of eight or higher. Although there are some minor changes in parameter estimates and levels of significance, our results remain largely unaltered.

${ }^{9}$ A corresponding table comparing the employed and non-employed males in the HILDA dataset is presented as Appendix 3. As expected, the employed posit different characteristics compared to the non-employed. Our definition of overeducated precludes the inclusion of non-employed males. 
the existence of an inverse relationship between overeducation and overall job satisfaction and satisfaction with pay.

As well, there is evidence to suggest that the overeducated are given tasks that they feel do not challenge their abilities (Burris, 1983) and that employers do not necessarily upgrade the tasks given to overeducated workers (Battu, et al., 2000). By definition, the overeducated have excess skills for their jobs, and hence, suffer from skill-underutilisation. We therefore also hypothesise an inverse relationship between overeducation and satisfaction with (type of) work.

The overeducated possess qualifications that exceed the requirements to do the job they have been assigned. It is expected that they require less training and supervision, and are thus, by implication, more likely to be valued compared to other employees (Hersch, 1995; Buchel, 2002). For this reason we hypothesis the existence of a positive relationship between overeducation and satisfaction with job security. ${ }^{10}$

Finally, our a priori expectation is that there exists no systematic relationship between overeducation and satisfaction with both hours of work and job flexibility. With both measures satisfaction might well be due to lifestyle choices rather than job match. For example, those in part-time or casual work might well be more satisfied with job flexibility. That this group are more likely to be overeducated is incidental to the nature of the satisfaction measure. Moreover, there are no previous findings in the literature concerning overeducation and these measures of satisfaction.

The percentage of Australian males in employment who are satisfied by various aspects of their work are shown in Figure 1. They are divided into overeducated and

\footnotetext{
${ }^{10}$ However, Battu et al. (2000) do not find that the overeducated are more likely to be valued by their employers. Our hypothesis in favour of Hersch (1995) and Buchel (2002) is strengthened by Kler's (2005b) finding that overeducated graduates in Australia are more likely to be satisfied with job security.
} 
non-overeducated groups. In general, results indicate that the overeducated are not as satisfied with various aspects of their workplace compared to the non-overeducated. However, the differences are not great, and for satisfaction with working hours in particular, the results are very similar.

This similarity in levels of satisfaction with working hours between the overeducated and non-overeducated is broadly consistent with the initial hypothesis that this measure is not sensitive to job match. However, we find no such indeterminate relationship between overeducation and job flexibility. Results on satisfaction with job security also do not match well with the initial hypothesis that the overeducated are more satisfied. However, results match the initial hypotheses that the overeducated will be overall less satisfied and less satisfied with their pay and type of work.

\section{Methodology}

\section{Univariate Probit}

A standard univariate probit model of the effect of overeducation on any given measure of workplace satisfaction is given as follows:

$S_{i}^{*}=\beta_{1} X_{i}+\beta_{2} W_{i}+$ soed $_{i}+\varepsilon_{1 i}$

Satisfaction at work is thus determined by an unobserved latent variable $S_{i}^{*}$, the value of which is dependent on personal characteristics $\left(X_{i}\right)$, employment characteristics $\left(W_{i}\right)$, and whether the individual is overeducated or otherwise $\left(\right.$ oed $\left._{i}\right) . \beta_{1}, \beta_{2}$ and $\delta$ are parameters to be estimated, while $\varepsilon_{1 i}$ represents a normally distributed error term with mean zero and variance one that captures the unobserved determinants of workplace satisfaction. The latent variable $S_{i}^{*}$ drives the observed outcome of being satisfied $S_{i}$, through the following measurement equation: 
$S_{i}= \begin{cases}1 & \text { if } S_{i}^{*}>0 \\ 0 & \text { if } S_{i}^{*} \leq 0\end{cases}$

The determinants of overeducation are also estimated via a univariate probit:

$\operatorname{oed}_{i}^{*}=\beta_{1} E_{i}+\beta_{2} X_{i}+\beta_{3} W_{i}+v_{1 i}$

Equation (3) looks at the determinants of overeducation by measuring the effects of educational $\left(E_{i}\right)$, personal $\left(X_{i}\right)$ and employment characteristics $\left(W_{i}\right)$. The $\beta$ s are parameters to be estimated, while $v_{1 i}$ (like $\varepsilon_{1 i}$ ) represents a normally distributed error term with mean zero and variance one. The latent variable oed $_{i}^{*}$ drives the observed outcome of being overeducated oed ${ }_{i}$ through the following measurement equation:

$\operatorname{oed}_{i}= \begin{cases}1 & \text { if } \text { oed }_{i}^{*}>0 \\ 0 & \text { if } \text { oed }_{i}^{*} \leq 0\end{cases}$

\section{Bivariate Probit}

Univariate probit results, however, could be potentially biased should there be an overlap in unobserved characteristics that determine both overeducation and workplace satisfaction (Greene, 1997; Alexandre and French, 2001; Alexandre and French, 2004; Deadman and MacDonald, 2004). This potential for unobserved heterogeneity could result in the error term in equation (1) being correlated with the explanatory variables that capture overeducation. If this should be the case, then overeducation will not be exogenous to workplace satisfaction. In short, the overeducation variable will capture not only the true effects of being overeducated but also the effect on workplace satisfaction of having this unobservable characteristic. ${ }^{11}$ This potential problem will be addressed below via a bivariate probit model:

\footnotetext{
${ }^{11}$ Correcting for potential endogeneity can also be done using the instrumental variable (IV) approach. However, there are shortcomings related to this approach that lead to a large trade-off between bias and variance. See for example Davidson and MacKinnon (1993), Bollen et al. (1995) and Norton (1998). Should weak correlation exist between the instruments and endogenously determined
} 
$S_{i}^{*}=\theta_{1}+\beta_{1} X_{i}+\beta_{2} W_{i}+$ ooed $_{i}+\varepsilon_{1 i}$

$\operatorname{oed}_{i}^{*}=\theta_{2}+\beta_{1} X_{i}+\beta_{2} W_{i}+\varsigma Z_{i}+v_{1 i}$

Equations (5) and (6) are bivariate probit models that estimate the relationship between workplace satisfaction and overeducation. The error terms $\varepsilon_{1 i}$ and $v_{1 i}$ are jointly distributed as bivariate normal with means zero, variances one and correlation $\rho$. The other variables are defined as in equations (1) and (3) while $Z_{i}$ is a vector of identifying restrictions. The $\beta s, \delta$ and $\varsigma$ represent parameters of interest. The variables that make up $Z_{i}$ are explained and discussed below.

\section{Identifying Restrictions in the Bivariate Probit}

One practical difficulty in attempting to estimate a bivariate probit is finding a set of identifying restrictions $\left(Z_{i}\right)$ that are significant determinants of the endogenous variable (in this case overeducation) but also orthogonal to the residuals of the main equation. This study has two identifying restrictions. The first identifying restriction separates Australian Born Residents (ABRs) and immigrants, with immigrants further subdivided into four groups by country of origin and time of arrival (ESB1, ESB2, NESB1, and NESB2). ${ }^{12}$ The second identifying restriction captures tenure with current employer (Tenure with Boss). A Hausman test was run and results indicate that the models with and without the identifying restrictions are significantly different from each other.

In support of our choice of the first identifying restriction, it is evident that immigrants to Australia are heterogeneous and possess sufficiently different characteristics to be separated into English speaking background (ESB) and NESB

\footnotetext{
explanatory variables, IV estimates can be seriously biased and in these cases the bivariate probit model is more appropriate and efficient (Greene, 1997; 1998).

${ }^{12}$ See Appendix 1 for definitions of these groups.
} 
groups (Beggs and Chapman, 1988; Cobb-Clark, 2003; Green, et al., 2006; Kler, 2006). Their abilities to assimilate into the Australian labour market differ widely, not just due to individual personal characteristics, but also due to the relative strength of the Australian labour market at their time of arrival. There is evidence to suggest ESB immigrants perform just as well in the labour market as ABRs (Tran-Nam and Nevile, 1988; Flatau, et al., 1995). However, Cobb-Clark (2003) and Junankar and Mahuteau (2005) find wage and employment success to be time variant. In a Canadian study, Bloom et al. (1995) report that immigrant's labour market success is partly attributable to country of origin and the labour market situation faced upon arrival. There is thus sufficient evidence to suggest that place of birth and (for immigrants) time of arrival are determinants of overeducation (Green, et al., 2006; Kler, 2006).

However, in unreported results, we find fairly uniform levels of satisfaction with the various measures of workplace satisfaction by place of birth. Moreover, the place of birth and time of arrival interaction variables are insignificant in the workplace satisfaction equations. We are therefore able to exclude this set of variables in the workplace satisfaction equations.

Turning to the choice of our second identifying restriction, tenure in current employment should affect the probability of a worker being overeducated if, as expected, overeducation is transitory for most individuals. ${ }^{13}$ We surmise that the longer an individual has been employed in one firm, the more likely he or she is going to be promoted out of their overeducated position into a position for which they are matched or even undereducated. Indeed we find that overeducated workers have 2.28 years less tenure than the undereducated and 1 year less than the adequately educated.

\footnotetext{
${ }^{13}$ See Alba-Ramirez (1993) and Battu et al. (1999) for evidence.
} 
Tenure in current employment does not, however, correlate strongly with measures of workplace satisfaction, with correlation rates of between 0.0063 and 0.0835 .

On the other hand, with respect to satisfaction with job security, we hypothesise that tenure in current employment would lead an employee to have a reasonable idea of their actual job security. Therefore it would not be appropriate as an identifying restriction in assessing this particular satisfaction measure.

\section{Econometric Results}

The following tables $(2-7)$ provide details of univariate and bivariate probit estimates on the determinants of overeducation and workplace satisfaction. Maximum likelihood estimators are reported for both univariate and bivariate probit models. The tables also report the results of the likelihood ratio test for the correlation estimator $\rho$.

Failure to reject the null hypothesis $(\rho=0)$ means that the univariate probit models will generate consistent estimates. Interpreting a rejection of the null hypothesis depends on the value of $\rho$. Should $\rho$ be significantly positive, then we can conclude that there is a positive correlation between the unobserved factors affecting both overeducation and job satisfaction. However, should $\rho$ be negative, the reverse is true. In either case the univariate results are likely to be biased.

Results for the overeducation equation in both the univariate and bivariate probit results are almost identical in all specifications. Hence, the overeducation equation will be discussed only for overeducation and overall job satisfaction.

\section{Overeducation and Overall Job Satisfaction}

The upper panel of Table 2 reports the coefficient estimates of the overeducation equation for both the univariate and bivariate probit models. Overall results are 
qualitatively similar for both models. Looking first at the variables that form the identifying restrictions $\left(Z_{i}\right)$, we find that long-term ESB immigrants are less likely to be overeducated compared to ABRs, while recent NESB immigrants are more likely to be overeducated; the latter is an intuitively plausible result and one consistent with earlier findings using the Longitudinal Survey of Immigrant Australians data set (see for example Green, et al., 2006; Kler, 2006). The only difference between the univariate and bivariate results concerns the second identifying restriction (Tenure with Boss). In the univariate probit model the relationship is insignificant, while in the bivariate model, at a 5\% level of significance, the longer the time spent with the current employer, the less likely a worker is to be overeducated.

Of the other variables, being a casual worker, working for a small firm and being a member of a union all increase the likelihood of a worker being overeducated, as does working in the manufacturing (as opposed to the private services) sector. In contrast, working in public services reduces the likelihood of being overeducated.

The lower panel of Table 2 reports the coefficient estimates of the overall job satisfaction equation for both the univariate and bivariate probit models. We find that the likelihood ratio test rejects the null hypothesis of independent equations at a $1 \%$ level of significance; this suggests that maximum likelihood estimates from the univariate probit model are biased. Specifically, the positive point estimate of $\rho$ implies that the unobserved factors affecting overeducation and overall job satisfaction are positively correlated.

Although it is unclear what causes this relationship, one possible explanation for overeducation being endogenous with respect to overall job satisfaction is that levels of job satisfaction may vary according to a job's skill-level requirements. That is, 
more lowly-skilled jobs may generate less job satisfaction, independent of whether one is overeducated for the job or not. In support of this hypothesis, in unreported results, we find that levels of satisfaction are higher for those in occupations with higher entry requirements compared to those with lower entry requirements. Nonetheless, overeducation decreases the likelihood of overall job satisfaction in both models, thus supporting the basic hypothesis.

Concentrating on the bivariate probit results we find the overeducated are $5.1 \%$ less likely to be job satisfied. This is consistent with both a priori expectations and those found by Tsang (1987), who reported an $11.6 \%$ fall in job satisfaction for every additional year of overeducation, and Tsang et al. (1991), who reported an inverse relationship between job satisfaction and surplus schooling. Hersch’s (1991) findings are also supportive of results in this sub-section; she reported that the overeducated are 3.15-3.69\% less likely to be satisfied with their jobs.

Of the other results, we find being a casual or public service worker to be the only variables that significantly affect overall job satisfaction; both groups are less satisfied with their jobs. Idson (1990) found employees in large firms to be less satisfied compared to employees of smaller sized firms. We however, find no significant differences in satisfaction between those employed in small, medium or large firms. The lack of significance of this and most other variables might be due to the heterogeneous nature of the 'overall job satisfaction' measure, since it asks respondents to take into account all the other satisfaction measures, many of which may not be consistent with each other.

\section{Overeducation and Satisfaction with Pay}

As in the previous section, the lower panel of Table 3 reports the coefficient estimates of the pay satisfaction equation for both the univariate and bivariate probit models. 
Again we find that the likelihood ratio test rejects the null hypothesis of independent equations at a $1 \%$ level of significance. Nonetheless, both models report less pay satisfaction for the overeducated in line with a priori expectations. In the bivariate probit model we find the overeducated to be $9.4 \%$ less likely to be satisfied with pay. Those in the public services are also less satisfied, while those in a de facto or married relationship and union members report higher pay satisfaction. ${ }^{14}$

\section{Overeducation and Satisfaction with Job Security}

In addition to our hypothesis of a positive relationship between overeducation and satisfaction with job security, we further hypothesise that the time a worker has spent with his current employer might well be positively related to satisfaction with job security. As a result, 'Tenure with Boss' has been included in the satisfaction with job security equations in both the univariate and bivariate probits. This leaves the place of birth variables (ESB1, ESB2, NESB1 and NESB2) as the only identifying restrictions in the bivariate probit model.

Looking at the results of the satisfaction with job security equation in the lower panel of Table 4, the likelihood ratio test indicates that the univariate probit model is unbiased. Hence, there is no reason to suspect that the bivariate model results are superior to those of the univariate models. Contrary to a priori expectations, we find that the overeducated are 3\% less satisfied with job security. Given the findings of Kler (2005b) this result might indicate that only the most qualified amongst the overeducated are valued by their employers.

In the univariate probit results for the other variables, we find casual workers and union members to be less satisfied with job security. Those in the public services and,

\footnotetext{
${ }^{14}$ The finding that union members report higher levels of satisfaction with pay is consistent with the findings of Meng (1990). Meng found members of unions in Canada to be more satisfied with both pay and (in contrast to our findings) job security than non-members.
} 
as expected, those with a longer time in current employment both report higher satisfaction levels.

\section{Overeducation and Satisfaction with Hours of Work}

In the lower panel of Table 5, the likelihood ratio test rejects the null hypothesis of independent equations at a $10 \%$ level of significance and the value of $\rho$ is positive. Thus we will again concentrate on results presented in the bivariate probit model. The model reports that the overeducated are $8.9 \%$ less likely to be satisfied with hours of work. This result is neither expected nor unexpected as we had no stated expectation with respect to satisfaction with hours. Of the other variables, we find that being a union member and being in the manufacturing sector increases satisfaction with hours of work, while being in the primary sector reduces satisfaction.

\section{Overeducation and Satisfaction with (type of) Work}

As with results for satisfaction with job security, the likelihood ratio test indicates that the univariate probit model is unbiased (see Table 6). In line with a priori expectations, according to the univariate probit model, the overeducated are $4 \%$ less likely to be satisfied with the type of work. Of the other variables, those in a de facto or married relationship and those working in primary industries are more satisfied with the type of work, while those in casual employment are less satisfied.

\section{Overeducation and Satisfaction with Job Flexibility}

As with tables 4 and 6, we once again find the univariate probit model to be unbiased (see Table 7). According to this model, overeducation decreases the likelihood of being satisfied with job flexibility by $6 \%$. As stated previously, we had no a priori expectations as to the relationship between overeducation and satisfaction with job flexibility. This study suggests an inverse relationship between the two variables. Of 
the other variables, part-time workers are more satisfied with job flexibility while casual workers, union members and those in primary industries are less satisfied.

\section{Discussion and Conclusion}

This paper has investigated the empirical relationship between overeducation and job satisfaction for Australian adult males. In a departure from much of the existing literature, both univariate and bivariate probit models are used to correct for possible bias in results. We find the univariate probit models to be positively biased in the case of overall job satisfaction, satisfaction with pay and satisfaction with hours of work. Overall, we can state that running the bivariate probit models improved the efficiency of the resulting estimates.

Our results show that across all measures of workplace satisfaction, overeducated workers in the Australian labour market are less satisfied compared to their nonovereducated counterparts, indicating that overeducated workers are not only less likely to be satisfied with their jobs as a whole, but also with more specific characteristics of their job. This is an important finding when we consider the nature of overeducation for an individual. As well, we provide initial evidence on an inverse relationship between overeducation and satisfaction with working hours and job flexibility.

Nevertheless, levels of workplace satisfaction amongst the overeducated remain high (see Figure 1). This intimates that satisfaction levels should be viewed from a relative, rather than an absolute, perspective (Clark and Oswald, 1996). From our findings we suggest that the overeducated are comparing themselves to their similarly educated peers who are in non-overeducated jobs, rather than to their immediate colleagues. 
In all, very little research has been done on this topic in Australia and further work is warranted. However, given the recent changes to the Australian workplace relations system, we note that future research would most probably be conducted in a very different working environment. A future study looking at levels of job satisfaction both pre- and post-reform would be of interest.

\section{Acknowledgements}

We would like to thank Jim Taylor, Rodney Beard and an anonymous referee for helpful feedback on an earlier draft and the Melbourne Institute and the Department of Family and Community Services for providing us with the HILDA dataset. Views expressed in this paper do not necessarily reflect those of the Melbourne Institute nor the Department of Family and Community Services. All errors and omissions remain our own. 


\section{References}

Alba-Ramirez, A. (1993) Mismatch in the Spanish labor market: Overeducation?, Journal of Human Resources, 28(2), 259-78.

Alexandre, P. and French, M. (2001) Labor supply of poor residents in metropolitan Miami, Florida: The role of depression and co-morbid effects of substance use, Journal of Mental Health Policy and Economics, 4(4), 161-73.

Alexandre, P. and French, M. (2004) Further evidence on the labor market effects of addiction: Chronic drug use and employment in metropolitan Miami, Contemporary Economic Policy, 22(3), 382-93.

Allen, J. and van der Velden, R. (2001) Educational mismatches versus skill mismatches: Effects on wages, job satisfaction, and on-the-job search, Oxford Economic Papers, 53(3), 434-52.

Andrews, K. (2005). Building Better Workplace Relations, [Online]. Available: http://mediacentre.dewr.gov.au/mediacentre/AllReleases/2005/May/BuildingBetterW orkplaceRelations.htm. Accessed 17 October 2005.

Battu, H., Belfield, C. and Sloane, P. (1999) Overeducation among graduates: A cohort view, Education Economics, 7(1), 21-38.

Battu, H., Belfield, C. and Sloane, P. (2000) How well can we measure graduate overeducation and its effects?, National Institute Economic Review, 171(1), 82-93.

Battu, H. and Sloane, P. (2004) Over-education and ethnic minorities in Britain, Manchester School, 72(4), 535-59.

Beggs, J. and Chapman, B. (1988) Immigrant wage adjustment in Australia: Cross section and time-series estimates, Economic Record, 64(186), 161-67.

Bloom, D., Grenier, G. and Gunderson, M. (1995) The changing labour market position of Canadian immigrants, Canadian Journal of Economics, 28(4b), 987-1005. 
Bollen, K., Guilkey, D. and Mroz, T. (1995) Bivariate outcomes and endogenous explanatory variables: Tests and solutions with an application to the demand for contraceptive use in Tunisia, Demography, 32(1), 111-31.

Buchel, F. (2002) The effects of overeducation on productivity in Germany - The firms' viewpoint, Economics of Education Review, 21(3), 263-75.

Burris, V. (1983) The social and political consequences of overeducation, American Sociological Review, 48(4), 454-67.

Clark, A. and Oswald, A. (1996) Satisfaction and comparison income, Journal of Public Economics, 61(3), 359-81.

Cobb-Clark, D. (2003) Public policy and the labor market adjustment of new immigrants to Australia, Journal of Population Economics, 16(4), 655-81.

Davidson, R. and MacKinnon, J. (1993) Estimation and Inference in Econometrics, Oxford University Press, New York.

Deadman, D. and MacDonald, Z. (2004) Offenders as victims of crime? An investigation into the relationship between criminal behaviour and victimization, Journal of the Royal Statistical Society Part A, 167(1), 53-67.

Duncan, G. and Hoffman, S. (1981) The incidence and wage effects of overeducation, Economics of Education Review, 1(1), 75-86.

Flatau, P., Petridis, R. and Wood, G. (1995) Immigrants and Invisible Underemployment, AGPS, Canberra.

Green, C., Kler, P. and Leeves, G. (2006) Overeducation and the assimilation of recently arrived immigrants: Evidence from Australia, Economics of Education Review, (forthcoming).

Greene, W. (1997) Econometric Analysis, Prentice Hall, London. 
Greene, W. (1998) Gender economics courses in liberal arts colleges: Further results, Journal of Economic Education, 29(4), 291-300.

Hartog, J. (2000) Over-education and earnings: Where are we, where should we go?, Economics of Education Review, 19(2), 131-47.

Hersch, J. (1991) Education match and job match, Review of Economics and Statistics, 73(1), $140-44$

Hersch, J. (1995) Optimal ‘mismatch’ and promotions, Economic Inquiry, 33(4), 611-24.

Idson, T. (1990) Establishment size, job satisfaction and the structure of work, Applied Economics, 22(8), 1007-18.

Junankar, P. and Mahuteau, S. (2005) Do migrants get good jobs? New migrant settlement in Australia, Economic Record, 81(special issue), S34-S46.

Kler, P. (2005a) Graduate overeducation in Australia: A comparison of the mean and objective methods, Education Economics, 13(1), 47-72.

Kler, P. (2005b) The impact of overeducation on job satisfaction and productivity amongst the tertiary qualified in Australia, Working paper, University of Queensland.

Kler, P. (2006) Graduate overeducation and its effects amongst recently arrived immigrants to Australia: A longitudinal survey, International Migration, (forthcoming).

Meng, R. (1990) The relationship between unions and job satisfaction, Applied Economics, 22(12), 1635-48.

Nelson, R. and Phelps, E. (1966) Investment in humans, technological diffusion, and economic growth, American Economic Review, 56(1-2), 69-75.

Norton, C., Lindrooth, R. and Ennett, S. (1998) Controlling for the endogeneity of peer substance use on adolescent alcohol and tobacco use, Health Economics, 7(5), 43953. 
OECD (Organisation for Economic Co-operation and Development) (2004) Education at a glance: OECD indicators 2004, Paris.

Schultz, T. (1975) The value of the ability to deal with disequilibria, Journal of Economic Literature, 13(3), 827-46.

Tran-Nam, B. and Nevile, J. (1988) The effects of birthplace on male earnings in Australia, Australian Economic Papers, 27(50), 83-101.

Tsang, M. (1987) The impact of underutilization of education on productivity: A case study of the U.S. Bell companies, Economics of Education Review, 6(3), 239-54.

Tsang, M. and Levin, H. (1985) The economics of overeducation, Economics of Education Review, 4(2), 93-104.

Tsang, M., Rumberger, R. and Levin, H. (1991) The impact of surplus schooling on worker productivity, Industrial Relations, 30(2), 209-28.

Verhaest, D. and Omey, E. (2004) The impact of overeducation and its measurement, Working Paper No. 215, Faculteit Economie En Bedrijfskunde, Ghent University.

Voon, D. and Miller, P. (2005) Undereducation and overeducation in the Australian labour market, Economic Record, 81(special issue), S22-S33.

Welch, F. (1970) Education in production, Journal of Political Economy, 78(1), 35-59.

Wooden, M., Freidin, S. and Watson, N. (2002) The Household, Income and Labour Dynamics in Australia (HILDA) Survey: Wave 1, Australian Economic Review, 35(3), 339-48. 
Table 1 Means and Standard Deviations By Education - Job Match Status

\begin{tabular}{|l|c|c|}
\hline Variables & Overeducated & Non-Overeducated \\
\hline Education Years & Means & Means \\
\hline Tenure with Boss & $14.07(0.94)$ & $13.2(1.98)$ \\
\hline Hourly Wage & $6.28(7.6)$ & $7.82(8.74)$ \\
\hline Age & $19.75(10.24)$ & $22.44(12.5)$ \\
\hline Couple & $37.16(10.9)$ & $38.93(11.49)$ \\
\hline Australian Born Resident & $0.68(0.47)$ & $0.72(0.45)$ \\
\hline ESB Immigrant 1 & $0.77(0.42)$ & $0.75(0.43)$ \\
\hline ESB Immigrant 2 & $0.075(0.26)$ & $0.1(0.31)$ \\
\hline NESB Immigrant 1 & $0.028(0.17)$ & $0.023(0.15)$ \\
\hline NESB Immigrant 2 & $0.081(0.27)$ & $0.091(0.29)$ \\
\hline Full-Time & $0.051(0.22)$ & $0.028(0.17)$ \\
\hline Part-Time & $0.87(0.33)$ & $0.91(0.29)$ \\
\hline Casual & $0.13(0.33)$ & $0.09(0.29)$ \\
\hline Small Sized Firm & $0.19(0.39)$ & $0.13(0.34)$ \\
\hline Medium Sized Firm & $0.33(0.47)$ & $0.29(0.45)$ \\
\hline Large Sized Firm & $0.31(0.46)$ & $0.31(0.46)$ \\
\hline Union Member & $0.36(0.48)$ & $0.4(0.49)$ \\
\hline Primary Industries & $0.33(0.47)$ & $0.31(0.46)$ \\
\hline Manufacturing & $0.061(0.24)$ & $0.072(0.26)$ \\
\hline Public Services & $0.2(0.4)$ & $0.15(0.36)$ \\
\hline Private Services & $0.09(0.29)$ & $0.18(0.38)$ \\
\hline Observations & $0.65(0.48)$ & $0.6(0.49)$ \\
\hline Standard errors are & 1030 & 1976 \\
\hline & & \\
\hline & & \\
\hline
\end{tabular}

Standard errors are in parentheses.

All results are rounded to two significant figures.

Categorical sub-sets may not add up to 1 due to rounding.

Source: HILDA Wave 1 dataset. 
Table 2 Overeducation and Overall Job Satisfaction

\begin{tabular}{|c|c|c|}
\hline VARIABLE & UNIVARIATE & BIVARIATE \\
\hline \multicolumn{3}{|l|}{ Overeducation } \\
\hline$\overline{\text { ESB } 1}$ & $-0.2^{* *}(0.86)$ & $-0.17 * *(0.081)$ \\
\hline ESB 2 & $0.083(0.15)$ & $0.014(0.14)$ \\
\hline NESB 1 & $-0.13(0.088)$ & $-0.053(0.096)$ \\
\hline NESB 2 & $0.3^{* *}(0.12)$ & $0.29 * *(0.12)$ \\
\hline Tenure with Boss & $-0.012(0.0085)$ & $-0.019 * *(0.008)$ \\
\hline Tenure with Boss ${ }^{2}$ & $0.00002(0.00027)$ & $0.00019(0.00026)$ \\
\hline Couple & $0.015(0.055)$ & $0.016(0.055)$ \\
\hline Part-Time & $0.097(0.088)$ & $0.096(0.088)$ \\
\hline Casual & $0.16^{* *}(0.078)$ & $0.14 *(0.079)$ \\
\hline Small Sized Firm & $0.12 * *(0.06)$ & $0.11 *(0.061)$ \\
\hline Medium Sized Firm & $0.017(0.059)$ & $0.0074(0.058)$ \\
\hline Union Member & $0.26 * * *(0.056)$ & $0.26 * * *(0.055)$ \\
\hline Primary Industries & $-0.16(0.098)$ & $-0.15(0.097)$ \\
\hline Manufacturing & $0.17 * * *(0.065)$ & $0.16^{* *}(0.066)$ \\
\hline Public Services & $-0.44 * * *(0.078)$ & $-0.44 * * *(0.076)$ \\
\hline Constant & $-0.44 * * *(0.07)$ & $-0.41 * * *(0.069)$ \\
\hline \multicolumn{3}{|c|}{ Overall Job Satisfaction } \\
\hline Overeducation & $-0.15^{* *}(0.06)$ & $-1.34 * * *(0.26)$ \\
\hline Couple & $0.098(0.065)$ & $0.075(0.06)$ \\
\hline Part-Time & $-0.067(0.1)$ & $-0.0066(0.096)$ \\
\hline Casual & $-0.31 * * *(0.089)$ & $-0.17 *(0.092)$ \\
\hline Small Sized Firm & $0.06(0.076)$ & $0.095(0.07)$ \\
\hline Medium Sized Firm & $-0.078(0.07)$ & $-0.055(0.065)$ \\
\hline Union Member & $-0.057(0.066)$ & $0.03(0.064)$ \\
\hline Primary Industries & $-0.093(0.12)$ & $-0.15(0.1)$ \\
\hline Manufacturing & $-0.12(0.08)$ & $-0.03(0.077)$ \\
\hline Public Services & $-0.057(0.088)$ & $-0.2^{* *}(0.085)$ \\
\hline Constant & $1.21 * * *(0.08)$ & $1.4^{* * *}(0.072)$ \\
\hline $\mathrm{P}$ & \multicolumn{2}{|c|}{0.71} \\
\hline$\chi^{2}$ for LR test of $\rho=0$ & \multicolumn{2}{|c|}{$9.65 * * *$} \\
\hline
\end{tabular}

$* * *, * *$ and $*$ denote 1,5 and 10 percent levels of significance respectively. Standard errors are in parentheses.

All results are rounded to two significant figures.

Source: HILDA Wave 1 dataset.

Omitted categories are Australian Born Residents (ABRs), Not Married or not in a de facto relationship, Full-Time, Large Sized Firm, Non-Union Member and Private Services. 
Table 3 Overeducation and Satisfaction with Pay

\begin{tabular}{|c|c|c|}
\hline VARIABLE & UNIVARIATE & BIVARIATE \\
\hline \multicolumn{3}{|l|}{ Overeducation } \\
\hline ESB 1 & $-0.2 * *(0.86)$ & $-0.17 * *(0.078)$ \\
\hline ESB 2 & $0.083(0.15)$ & $0.072(0.13)$ \\
\hline NESB 1 & $-0.13(0.088)$ & $-0.068(0.08)$ \\
\hline NESB 2 & $0.3^{* *}(0.12)$ & $0.33 * * *(0.11)$ \\
\hline Tenure with Boss & $-0.012(0.0085)$ & $-0.016 * *(0.0076)$ \\
\hline Tenure with Boss ${ }^{2}$ & $0.00002(0.00027)$ & $0.00007(0.00025)$ \\
\hline Couple & $0.015(0.055)$ & $0.052(0.057)$ \\
\hline Part-Time & $0.097(0.088)$ & $0.12(0.089)$ \\
\hline Casual & $0.16^{* *}(0.078)$ & $0.14 *(0.079)$ \\
\hline Small Sized Firm & $0.12 * *(0.06)$ & $0.12 * *(0.06)$ \\
\hline Medium Sized Firm & $0.017(0.059)$ & $0.013(0.058)$ \\
\hline Union Member & $0.26 * * *(0.056)$ & $0.27 * * *(0.054)$ \\
\hline Primary Industries & $-0.16(0.098)$ & $-0.17 * * *(0.098)$ \\
\hline Manufacturing & $0.17 *(0.065)$ & $0.18 * * *(0.064)$ \\
\hline Public Services & $-0.44 * * *(0.078)$ & $-0.45 * * *(0.076)$ \\
\hline Constant & $-0.44 * * *(0.07)$ & $-0.45 * * *(0.069)$ \\
\hline \multicolumn{3}{|l|}{ Pay Satisfaction } \\
\hline Overeducation & $-0.12 * *(0.0527)$ & $-1.38 * * *(0.16)$ \\
\hline Couple & $0.17 * * *(0.0559)$ & $0.12 * *(0.055)$ \\
\hline Part-Time & $-0.13(0.0903)$ & $-0.052(0.085)$ \\
\hline Casual & $-0.12(0.0793)$ & $0.011(0.08)$ \\
\hline Small Sized Firm & $-0.081(0.0637)$ & $-0.018(0.059)$ \\
\hline Medium Sized Firm & $-0.075(0.061)$ & $-0.049(0.056)$ \\
\hline Union Member & $0.034(0.0569)$ & $0.12 * *(0.052)$ \\
\hline Primary Industries & $-0.032(0.101)$ & $-0.099(0.095)$ \\
\hline Manufacturing & $0.023(0.0702)$ & $0.093(0.063)$ \\
\hline Public Services & $-0.13 *(0.0746)$ & $-0.28 * * *(0.071)$ \\
\hline Constant & $0.68 * * *(0.0689)$ & $0.94 * * *(0.064)$ \\
\hline$\rho$ & \multicolumn{2}{|c|}{0.78} \\
\hline$\chi^{2}$ for LR test of $\rho=0$ & \multicolumn{2}{|c|}{$17.39^{* * *}$} \\
\hline
\end{tabular}

***, ** and * denote 1,5 and 10 percent levels of significance respectively. Standard errors are in parentheses.

All results are rounded to two significant figures.

Source: HILDA Wave 1 dataset.

Omitted categories are Australian Born Residents (ABRs), Not Married or not in a de facto relationship, Full-Time, Large Sized Firm, Non-Union Member and Private Services. 
Table 4 Overeducation and Satisfaction with Job Security

\begin{tabular}{|c|c|c|}
\hline VARIABLE & UNIVARIATE & BIVARIATE \\
\hline \multicolumn{3}{|l|}{ Overeducation } \\
\hline ESB 1 & $-0.2 * *(0.86)$ & $-0.15(0.095)$ \\
\hline ESB 2 & $0.083(0.15)$ & $0.092(0.15)$ \\
\hline NESB 1 & $-0.13(0.088)$ & $-0.1(0.088)$ \\
\hline NESB 2 & $0.3^{* *}(0.12)$ & $0.34 * * *(0.12)$ \\
\hline Tenure with Boss & $-0.012(0.0085)$ & $-0.012(0.008)$ \\
\hline Tenure with Boss ${ }^{2}$ & $0.00002(0.00027)$ & $-0.0000028(0.00027)$ \\
\hline Couple & $0.015(0.055)$ & $0.013(0.055)$ \\
\hline Part-Time & $0.097(0.088)$ & $0.092(0.089)$ \\
\hline Casual & $0.16^{* *}(0.078)$ & $0.17 * *(0.078)$ \\
\hline Small Sized Firm & $0.12 * *(0.06)$ & $0.12 * * *(0.061)$ \\
\hline Medium Sized Firm & $0.017(0.059)$ & $0.02(0.058)$ \\
\hline Union Member & $0.26 * * *(0.056)$ & $0.26 * * *(0.056)$ \\
\hline Primary Industries & $-0.16(0.098)$ & $-0.15(0.099)$ \\
\hline Manufacturing & $0.17 * * *(0.065)$ & $0.17 * * *(0.065)$ \\
\hline Public Services & $-0.44 * * *(0.078)$ & $-0.44 * * *(0.077)$ \\
\hline Constant & $-0.44 *(0.07)$ & $-0.44 * * *(0.069)$ \\
\hline \multicolumn{3}{|l|}{ Job Security Satisfaction } \\
\hline Tenure with Boss & $0.018 *(0.0096)$ & $0.011(0.01)$ \\
\hline Tenure with Boss ${ }^{2}$ & $-0.00035(0.0003)$ & $-0.00027(0.00029)$ \\
\hline Overeducation & $-0.11^{* *}(0.056)$ & $-1.018 * *(0.49)$ \\
\hline Couple & $-0.073(0.062)$ & $-0.066(0.059)$ \\
\hline Part-Time & $-0.012(0.099)$ & $0.026(0.095)$ \\
\hline Casual & $-0.6 * * *(0.083)$ & $-0.49 * * *(0.12)$ \\
\hline Small Sized Firm & $-0.025(0.068)$ & $0.013(0.069)$ \\
\hline Medium Sized Firm & $0.0065(0.066)$ & $0.011(0.62)$ \\
\hline Union Member & $-0.11 *(0.063)$ & $-0.022(0.079)$ \\
\hline Primary Industries & $-0.03(0.11)$ & $-0.076(0.1)$ \\
\hline Manufacturing & $-0.1(0.073)$ & $-0.038(0.081)$ \\
\hline Public Services & $0.21 * *(0.087)$ & $0.076(0.11)$ \\
\hline Constant & $1.024 * * *(0.08)$ & $1.24 * * *(0.097)$ \\
\hline$\rho$ & \multicolumn{2}{|c|}{0.55} \\
\hline$\chi^{2}$ for LR test of $\rho=0$ & \multicolumn{2}{|c|}{2.22} \\
\hline
\end{tabular}

$* * *, * *$ and $*$ denote 1,5 and 10 percent levels of significance respectively. Standard errors are in parentheses.

All results are rounded to two significant figures.

Source: HILDA Wave 1 dataset.

Omitted categories are Australian Born Residents (ABRs), Not Married or not in a de facto relationship, Full-Time, Large Sized Firm, Non-Union Member and Private Services. 
Table 5 Overeducation and Satisfaction with Hours of Work

\begin{tabular}{|c|c|c|}
\hline VARIABLE & UNIVARIATE & BIVARIATE \\
\hline \multicolumn{3}{|l|}{ Overeducation } \\
\hline ESB 1 & $-0.12 * *(0.86)$ & $-0.16 * *(0.078)$ \\
\hline ESB 2 & $0.083(0.15)$ & $0.13(0.13)$ \\
\hline NESB 1 & $-0.13(0.088)$ & $-0.13 *(0.077)$ \\
\hline NESB 2 & $0.3^{* *}(0.12)$ & $0.3 *(0.12)$ \\
\hline Tenure with Boss & $-0.012(0.0085)$ & $-0.00059(0.01)$ \\
\hline Tenure with Boss ${ }^{2}$ & $0.00002(0.00027)$ & $-0.00028(0.00029)$ \\
\hline Couple & $0.015(0.055)$ & $0.0045(0.054)$ \\
\hline Part-Time & $0.097(0.088)$ & $0.12(0.085)$ \\
\hline Casual & $0.16^{* *}(0.078)$ & $0.18 * *(0.076)$ \\
\hline Small Sized Firm & $0.12 * *(0.06)$ & $0.12 * *(0.06)$ \\
\hline Medium Sized Firm & $0.017(0.059)$ & $0.016(0.058)$ \\
\hline Union Member & $0.26 *(0.056)$ & $0.25 * * *(0.055)$ \\
\hline Primary Industries & $-0.16(0.098)$ & $-0.16(0.095)$ \\
\hline Manufacturing & $0.17 * * *(0.065)$ & $0.16^{* *}(0.067)$ \\
\hline Public Services & $-0.44 * * *(0.078)$ & $-0.45 * * *(0.075)$ \\
\hline Constant & $-0.44 * * *(0.07)$ & $-0.48 * * *(0.071)$ \\
\hline \multicolumn{3}{|l|}{ Hours Satisfaction } \\
\hline Overeducation & $-0.063(0.053)$ & $-1.38 * * *(0.35)$ \\
\hline Couple & $-0.071(0.057)$ & $-0.072(0.052)$ \\
\hline Part-Time & $-0.22 * *(0.088)$ & $-0.12(0.09)$ \\
\hline Casual & $0.0099(0.078)$ & $0.12(0.08)$ \\
\hline Small Sized Firm & $0.035(0.064)$ & $0.079(0.059)$ \\
\hline Medium Sized Firm & $0.0021(0.061)$ & $0.017(0.056)$ \\
\hline Union Member & $0.083(0.057)$ & $0.16 * * *(0.053)$ \\
\hline Primary Industries & $-0.15(0.098)$ & $-0.2 * *(0.088)$ \\
\hline Manufacturing & $0.12(0.071)$ & $0.17 * *(0.066)$ \\
\hline Public Services & $0.099(0.076)$ & $-0.1(0.091)$ \\
\hline Constant & $0.71 * * *(0.069)$ & $0.96 * * *(0.062)$ \\
\hline$\rho$ & \multicolumn{2}{|c|}{0.81} \\
\hline$\chi^{2}$ for LR test of $\rho=0$ & \multicolumn{2}{|c|}{$3.32 *$} \\
\hline
\end{tabular}

***, ** and * denote 1,5 and 10 percent levels of significance respectively. Standard errors are in parentheses.

All results are rounded to two significant figures.

Source: HILDA Wave 1 dataset.

Omitted categories are Australian Born Residents (ABRs), Not Married or not in a de facto relationship, Full-Time, Large Sized Firm, Non-Union Member and Private Services. 
Table 6 Overeducation and Satisfaction with (type of) Work

\begin{tabular}{|c|c|c|}
\hline VARIABLE & UNIVARIATE & BIVARIATE \\
\hline \multicolumn{3}{|l|}{ Overeducation } \\
\hline ESB 1 & $-0.2 * *(0.86)$ & $-0.18 * *(0.087)$ \\
\hline ESB 2 & $0.083(0.15)$ & $0.075(0.15)$ \\
\hline NESB 1 & $-0.13(0.088)$ & $-0.12(0.088)$ \\
\hline NESB 2 & $0.3^{* *}(0.12)$ & $0.29 * *(0.12)$ \\
\hline Tenure with Boss & $-0.012(0.0085)$ & $-0.014 *(0.0083)$ \\
\hline Tenure with Boss ${ }^{2}$ & $0.00002(0.00027)$ & $0.00005(0.00026)$ \\
\hline Couple & $0.015(0.055)$ & $0.015(0.055)$ \\
\hline Part-Time & $0.097(0.088)$ & $0.09(0.089)$ \\
\hline Casual & $0.16^{* *}(0.078)$ & $0.16^{* *}(0.078)$ \\
\hline Small Sized Firm & $0.12 * *(0.06)$ & $0.12 *(0.061)$ \\
\hline Medium Sized Firm & $0.017(0.059)$ & $0.014(0.059)$ \\
\hline Union Member & $0.26 * * *(0.056)$ & $0.26 * * *(0.056)$ \\
\hline Primary Industries & $-0.16(0.098)$ & $-0.15(0.098)$ \\
\hline Manufacturing & $0.17 * * *(0.065)$ & $0.17^{* *}(0.066)$ \\
\hline Public Services & $-0.44 * * *(0.078)$ & $-0.44 * * *(0.077)$ \\
\hline Constant & $-0.44 * * *(0.07)$ & $-0.43 * * *(0.07)$ \\
\hline \multicolumn{3}{|l|}{ Work Satisfaction } \\
\hline Overeducation & $-0.18 * * *(0.06)$ & $-0.94 * *(0.46)$ \\
\hline Couple & $0.11 *(0.063)$ & $0.095(0.062)$ \\
\hline Part-Time & $-0.042(0.1)$ & $-0.0061(0.1)$ \\
\hline Casual & $-0.3^{* * *}(0.088)$ & $-0.22 * *(0.1)$ \\
\hline Small Sized Firm & $0.1(0.075)$ & $0.13 *(0.072)$ \\
\hline Medium Sized Firm & $-0.0086(0.069)$ & $0.00082(0.067)$ \\
\hline Union Member & $-0.056(0.064)$ & $0.0019(0.071)$ \\
\hline Primary Industries & $0.29 * *(0.13)$ & $0.22 *(0.13)$ \\
\hline Manufacturing & $-0.1(.078)$ & $-0.049(0.083)$ \\
\hline Public Services & $0.03(0.088)$ & $-0.079(0.1)$ \\
\hline Constant & $1.099 * * *(0.078)$ & $1.27 * * *(0.097)$ \\
\hline$\rho$ & \multicolumn{2}{|c|}{0.47} \\
\hline$\chi^{2}$ for LR test of $\rho=0$ & \multicolumn{2}{|c|}{2.11} \\
\hline
\end{tabular}

***, ** and * denote 1,5 and 10 percent levels of significance respectively. Standard errors are in parentheses.

All figures are rounded to two significant figures.

Source: HILDA Wave 1 dataset.

Omitted categories are Australian Born Residents (ABRs), Not Married or not in a de facto relationship, Full-Time, Large Sized Firm, Non-Union Member and Private Services. 
Table 7 Overeducation and Satisfaction with Job Flexibility

\begin{tabular}{|c|c|c|}
\hline VARIABLE & UNIVARIATE & BIVARIATE \\
\hline \multicolumn{3}{|l|}{ Overeducation } \\
\hline ESB 1 & $-0.2 * *(0.86)$ & $-0.18 * *(0.091)$ \\
\hline ESB 2 & $0.083(0.15)$ & $0.08(0.15)$ \\
\hline NESB 1 & $-0.13(0.088)$ & $-0.13(0.087)$ \\
\hline NESB 2 & $0.3^{* *}(0.12)$ & $0.29 * *(0.13)$ \\
\hline Tenure with Boss & $-0.012(0.0085)$ & $-0.013(0.0087)$ \\
\hline Tenure with Boss ${ }^{2}$ & $0.00002(0.00027)$ & $0.000045(0.00028)$ \\
\hline Couple & $0.015(0.055)$ & $0.015(0.055)$ \\
\hline Part-Time & $0.097(0.088)$ & $0.097(0.088)$ \\
\hline Casual & $0.16^{* *}(0.078)$ & $0.16^{* *}(0.078)$ \\
\hline Small Sized Firm & $0.12 * *(0.06)$ & $0.12 * *(0.061)$ \\
\hline Medium Sized Firm & $0.017(0.059)$ & $0.017(0.059)$ \\
\hline Union Member & $0.26 * * *(0.056)$ & $0.26 * * *(0.056)$ \\
\hline Primary Industries & $-0.16(0.098)$ & $-0.16(0.098)$ \\
\hline Manufacturing & $0.17 * * *(0.065)$ & $0.17 * * *(0.065)$ \\
\hline Public Services & $-0.44 * * *(0.078)$ & $-0.44 * * *(0.078)$ \\
\hline Constant & $-0.4 \$ * * *(0.07)$ & $-0.43 * * *(0.07)$ \\
\hline \multicolumn{3}{|c|}{ Job Flexibility Satisfaction } \\
\hline Overeducation & $-0.19 * * *(0.053)$ & $-0.62(0.66)$ \\
\hline Couple & $-0.024(0.057)$ & $-0.029(0.057)$ \\
\hline Part-Time & $0.47 * * *(0.1)$ & $0.48 * * *(0.01)$ \\
\hline Casual & $-0.28 * * *(0.08)$ & $-0.24 * *(0.11)$ \\
\hline Small Sized Firm & $0.032(0.064)$ & $0.048(0.068)$ \\
\hline Medium Sized Firm & $0.016(0.061)$ & $0.02(0.061)$ \\
\hline Union Member & $-0.16 * * *(0.056)$ & $-0.12(0.08)$ \\
\hline Primary Industries & $-0.2 * *(0.098)$ & $-0.23 * *(0.099)$ \\
\hline Manufacturing & $-0.014(0.07)$ & $0.013(0.079)$ \\
\hline Public Services & $0.1(0.078)$ & $0.036(0.13)$ \\
\hline Constant & $0.79 * * *(0.07)$ & $0.91^{* * *}(0.17)$ \\
\hline$\rho$ & \multicolumn{2}{|c|}{0.27} \\
\hline$\chi^{2}$ for LR test of $\rho=0$ & \multicolumn{2}{|c|}{0.39} \\
\hline
\end{tabular}

***, ** and * denote 1,5 and 10 percent levels of significance respectively. Standard errors are in parentheses.

All figures are rounded to two significant figures.

Source: HILDA Wave 1 dataset.

Omitted categories are Australian Born Residents (ABRs), Not Married or not in a de facto relationship, Full-Time, Large Sized Firm, Non-Union Member and Private Services. 
Figure 1 Workplace Satisfaction Measures by Education - Job Match

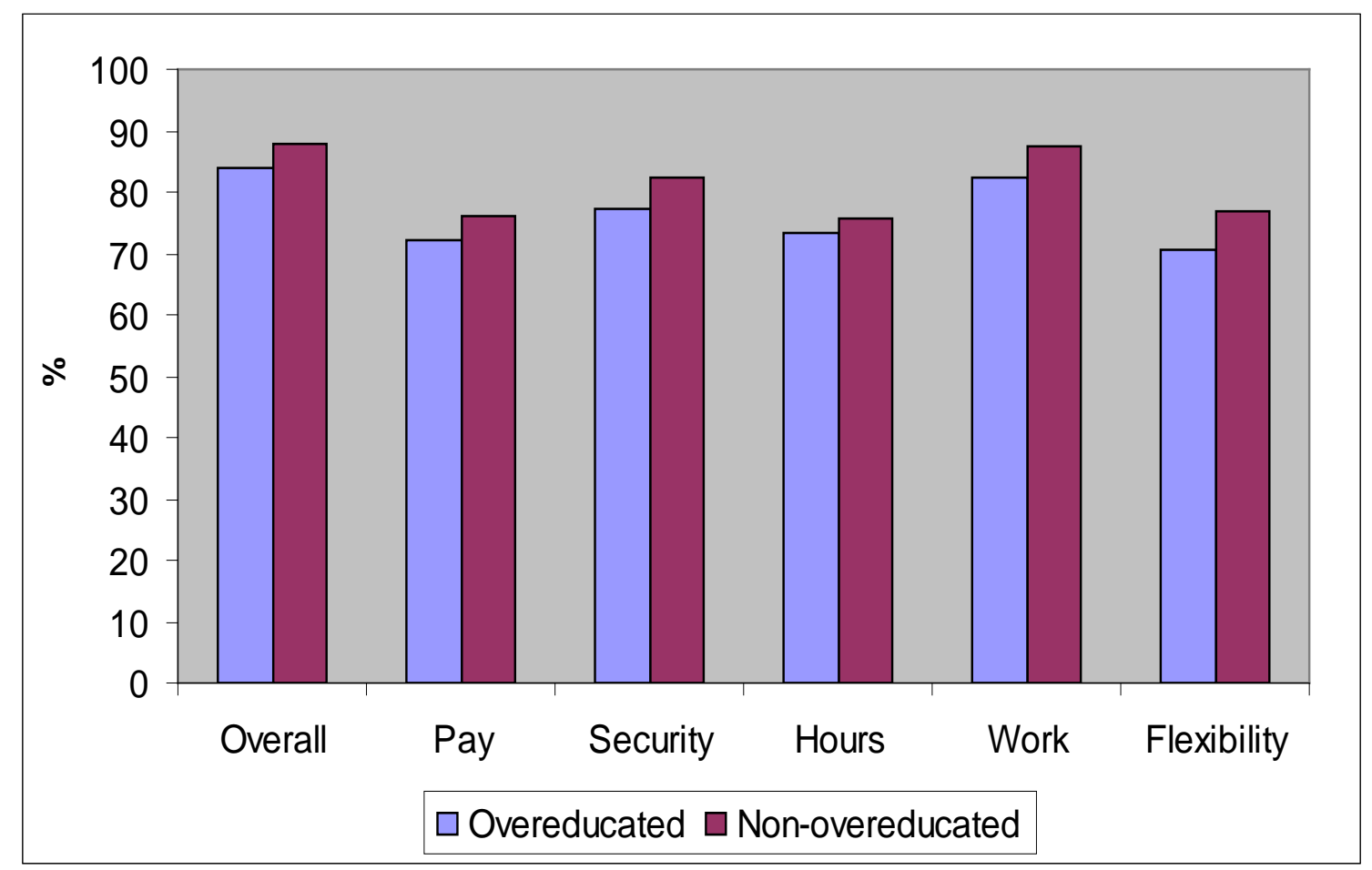

Source: HILDA Wave 1 dataset. 
Appendix 1: Variable List and Definitions

\begin{tabular}{|c|c|}
\hline VARIABLE & DESCRIPTION \\
\hline \multicolumn{2}{|l|}{ Dependent Variables } \\
\hline Overeducated & Dummy variable (DV) = 1 if individual has surplus education to do their job \\
\hline Non-Overeducated & DV = 1 if individual has no surplus education (Omitted Category) \\
\hline Overall Job Satisfaction & $\mathrm{DV}=1$ if individual is satisfied with the job, all things considered \\
\hline Pay Satisfaction & $\mathrm{DV}=1$ if individual is satisfied with pay \\
\hline $\begin{array}{ll}\text { Job } & \text { Security } \\
\text { Satisfaction } & \end{array}$ & $\mathrm{DV}=1$ if individual is satisfied with job security \\
\hline Hours Satisfaction & DV = 1 if individual is satisfied with hours worked \\
\hline Work Satisfaction & $\mathrm{DV}=1$ if individual is satisfied with the work itself \\
\hline $\begin{array}{ll}\text { Job } & \text { Flexibility } \\
\text { Satisfaction } & \\
\end{array}$ & $\begin{array}{l}\text { DV = } 1 \text { if individual is satisfied with the balance between work and other } \\
\text { commitments }\end{array}$ \\
\hline \multicolumn{2}{|l|}{ Identifying Restrictions } \\
\hline ESB1 & $\begin{array}{l}\text { DV = } 1 \text { if individual is born in the UK, Ireland, NZ, Canada, USA, South } \\
\text { Africa or Zimbabwe and immigrated to Australia prior to } 1991\end{array}$ \\
\hline ESB2 & $\begin{array}{l}\text { DV = } 1 \text { if individual is born in the UK, Ireland, NZ, Canada, USA, South } \\
\text { Africa or Zimbabwe and immigrated to Australia in } 1991 \text { or later }\end{array}$ \\
\hline NESB1 & $\begin{array}{l}\text { DV = } 1 \text { if individual is born outside of Australia, UK, Ireland, NZ, Canada, } \\
\text { USA, South Africa or Zimbabwe and immigrated to Australia prior to } 1991\end{array}$ \\
\hline NESB2 & $\begin{array}{l}\text { DV = } 1 \text { if individual is born outside of Australia, UK, Ireland, NZ, Canada, } \\
\text { USA, South Africa or Zimbabwe and immigrated to Australia in } 1991 \text { or } \\
\text { later }\end{array}$ \\
\hline ABR & $\mathrm{DV}=1$ if individual is Australian born (omitted) \\
\hline Tenure with Boss & $\begin{array}{l}\text { Discrete variable measuring the total years of an individual's tenure with } \\
\text { his/her current employer }\end{array}$ \\
\hline Tenure with Boss ${ }^{2}$ & $\begin{array}{l}\text { Discrete variable measuring the total years of an individual's tenure with } \\
\text { his/her current employer squared }\end{array}$ \\
\hline \multicolumn{2}{|l|}{ Other Variables } \\
\hline Couple & $\mathrm{DV}=1$ if individual is in a de facto or married relationship, zero otherwise \\
\hline Part-Time & DV = 1 if individual is working less than 35 hours a week \\
\hline Full-Time & DV = 1 if individual working at least 35 hours a week (Omitted Category) \\
\hline Casual & $\mathrm{DV}=1$ if individual is on a casual contract, zero otherwise \\
\hline Small Sized Firm & DV = 1 if individual works in a firm with less than 10 employees \\
\hline Medium Sized Firm & $\mathrm{DV}=1$ if individual works in a firm between 10 and 49 employees \\
\hline Large Sized Firm & $\begin{array}{l}\text { DV = } 1 \text { if individual works in a firm with more than } 49 \text { employees (Omitted } \\
\text { Category) }\end{array}$ \\
\hline Union Member & $\mathrm{DV}=1$ if individual is a union member, zero otherwise \\
\hline Primary Industries & DV $=1$ if individual works in the primary industries \\
\hline Manufacturing & $\mathrm{DV}=1$ if individual works in the manufacturing industry \\
\hline Public Services & DV $=1$ if individual works in the public services \\
\hline Private Services & DV = 1 if individual works in the private services (Omitted Category) \\
\hline
\end{tabular}




\section{Appendix 2: Workplace Satisfaction Question in the HILDA Person Questionnaire}

E36 I now have some questions about how satisfied or dissatisfied you are with different aspects of your job.

If not currently employed: These questions refer to the most recent job you were working in the last 7 days.

I am going to read out a list of different aspects of your job and, using the scale on SHOWCARD 36, I want you to pick a number between 0 and 10 to indicate how satisfied or dissatisfied you are with the following aspects of your job. The more satisfied you are, the higher the number you should pick. The less satisfied you are, the lower the number.

a Your total pay

b Your job security

c The work itself (what you do)

d The hours you work

e The flexibility available to balance work and non-work commitments

f All things considered, how satisfied are you with your job? 
Appendix 3: Means and Standard Deviations - Employed and NonEmployed Males

\begin{tabular}{|l|c|c|}
\hline Variables & Employed & Non-Employed \\
\hline & Means & Means \\
\hline Education Years & $13.50(1.74)$ & $12.66(1.64)$ \\
\hline Age & $38.33(11.32)$ & $43.92(15.21)$ \\
\hline Couple & $0.71(0.46)$ & $0.54(0.50)$ \\
\hline Australian Born Resident & $0.76(0.43)$ & $0.68(0.47)$ \\
\hline ESB Immigrant 1 & $0.094(0.29)$ & $0.095(0.29)$ \\
\hline ESB Immigrant 2 & $0.025(0.15)$ & $0.014(0.12)$ \\
\hline NESB Immigrant 1 & $0.087(0.28)$ & $0.14(0.35)$ \\
\hline NESB Immigrant 2 & $0.036(0.19)$ & $0.073(0.26)$ \\
\hline Observations & 1030 & 1976 \\
\hline Standard errors are in para
\end{tabular}

Standard errors are in parentheses.

All results are rounded to two significant figures.

Categorical sub-sets may not add up to 1 due to rounding.

Source: HILDA Wave 1 dataset. 